University of Windsor

Scholarship at UWindsor

$6-2002$

\title{
So, How Do People Really Use Their Handheld Devices? An Interactive Study of Wireless Technology Use
}

Francine K. Schlosser

Odette School of Business, University of Windsor

Follow this and additional works at: https://scholar.uwindsor.ca/odettepub

Part of the Business Commons

\section{Recommended Citation}

Schlosser, Francine K.. (2002). So, How Do People Really Use Their Handheld Devices? An Interactive Study of Wireless Technology Use. Journal of Organizational Behavior, 23 (4), 401-423.

https://scholar.uwindsor.ca/odettepub/109

This Article is brought to you for free and open access by the Odette School of Business at Scholarship at UWindsor. It has been accepted for inclusion in Odette School of Business Publications by an authorized administrator of Scholarship at UWindsor. For more information, please contact scholarship@uwindsor.ca. 


\title{
So, how do people really use their handheld devices? An interactive study of wireless technology use ${ }^{\dagger}$
}

\author{
FRANCINE K. SCHLOSSER*
}

University of Waterloo, Canada

\begin{abstract}
Summary Using a symbolic interactionist methodology, the diverse meanings assigned by employees to wireless handheld technology are investigated. Interviews were conducted with 11 individuals representing three organizations in the public and private sector enhancing our understanding of technology use within an organizational context. Wireless technology practices are examined as they relate to aspects of self-identity, that is, the imaged self, the relational self, the integrated self and the isolated self. Individuals were able to fit the technology into their work and personal roles, and at the same time, adjusted these roles to fit new expectations arising from the technology. Innovative ways of using the technology were shaped by individual needs as users adapted their message contexts, social etiquette, self-impressions, and ways of doing business. A need to self-regulate emerged with high expectations of availability and the blurring of multiple work and personal roles. Copyright (C) 2002 John Wiley \& Sons, Ltd.
\end{abstract}

\section{Introduction}

The most important lesson that can be learned from seeing the different emphases that different civilizations attach to technology is that this process is determined as much by the nature of the tool-user as by the nature of the tool. Rybczynski, 1983, p. 210.

We have entered a new era of workplace connectivity through the advent of portable wireless technologies. These tools will provide needed flexibility to juggle work and family aspects of our selfidentities, and provide the needed control to preserve this sense of self. However, in this fast-forward age, they may also blur traditional boundaries to such a degree, that the lines delineating our sense of self will become shadowy and inconsequential. Just as our greatest strength is often our greatest weakness, we may find that the challenges involved in harnessing technology within our own personal and organizational context will create a much stronger sense of self. How then, do normal people who find

* Correspondence to: Francine K. Schlosser, Department of Management Sciences, University of Waterloo, 200 University Avenue West, Waterloo, ON, N2L 3G1, Canada. E-mail: schloss@golden.net

${ }^{\dagger}$ Portions of this paper were presented at the 2001 18th Qualitative Research Conference, McMaster University, Hamilton, ON, Canada. 
themselves on the frontline perceive wireless handheld devices and how has use affected their sense of self? In the current study, we investigate the meaning that each individual gives to wireless handheld technology. We examine this question from a multi-faceted perspective including aspects surrounding relational, imaged, integrated and isolated selves. The meaning given to technology and the development of technology-practices surrounding technology gives rise to a continuous cycle of innovation through use.

The goals of this research are to investigate the meaning that individuals give to wireless handheld technology within an organizational context. This includes a consideration of the changes to wireless technology-practice and to traditional personal-work boundaries utilizing a symbolic interactionist viewpoint and methodology. A methodology identifying key 'generic social processes' underpins the study's theoretical framework. As it relates to the subjectivist interactionist research process, Prus (1997) pioneered this concept of categorizing group life and suggested that all forms of human activity, occurring within many various subcultures, could be analysed and grouped within similar, or generic, categories.

Wireless handheld devices have become a part of the North American lifestyle. Eadie (2001) reported that more than half of North Americans-61 per cent of Americans and 41 per cent of Canadians - have used wireless devices. Of these, 91 per cent have used a mobile phone and 27.5 per cent a pager. These devices have evolved from basic paging, telephone, and scheduling technologies to active messaging: for instance, Internet-enabled handheld computers (e.g. Palm Pilot and RIM's BlackBerry) currently allow individuals to send and receive wireless communications. However, there has been little investigation into the ways in which employees are adapting to these wireless technologies. Thus, this study will be provisional and exploratory in nature and will address the need for this type of research given the limited nature of past research on the meanings and uses of wireless technology.

This research responds to Orlikowski and Iacono's (2001) suggestion for increased research into the 'ensemble' view of technology (which considers technology as embedded within the larger social context) because there has been little work to date in this area. Orlikowski and Iacono (2001, p. 121) defined IT artefacts as 'those bundles of material and cultural properties packaged in some socially recognizable form such as hardware and/or software.' Upon reviewing past studies of technology performed over the past ten years, they concluded that these artefacts must be viewed within their cultural and historical context, and as dynamic and continually evolving products.

Further, although there has been some research on the design of wireless technologies (Dix et al., 2000) and, more generally, on factors affecting employee acceptance of information systems (e.g., Taylor \& Todd, 1995), little previous behavioral studies on wireless technologies exist. Palen, Salzman, and Youngs (2000) discussed some of the social conflicts mobile phone users experience when they make choices between their physical and conversational space, that is, how to fit the mobile cellphone use into their current physical and social context. They also noted that the more experience one has using mobile telephony, the broader one's social tolerance of its use. This suggests a need to examine how employees interpret wireless technologies in the workplace. Despite this dearth of behavioral wireless research, several other streams of research — on technology adoption and use and social influences-will help to inform study results.

With this in mind, the current paper will review past literature on symbolic interactionism, and related social theory. From these, a framework of relevant themes will be developed which will increase our understanding of how the introduction of pervasive forms of technology (such as these wireless technology devices actually worn by an individual) might influence employee attitudes. The methodology surrounding the ethnographic interviews conducted in the study will be reviewed, and the participating organizations profiled for the reader. Results of the interviews will provide both a conceptual explanation of each theme supported by key quotes from study participants. I will follow 
with a discussion of the findings, including academic and practical implications, and conclude with contributions, limitations and suggestions for future research.

\section{Symbolic interactionism}

Qualitative research allows us to broaden our concept of technology, similar to the way the early Greeks defined the concept of techné, as 'an enacted feature of the human condition' (Prus \& Mitchell, 2000 , p. 1 - submitted). In this way, we delve past a superficial level of technology use to arrive at how people change themselves and their routines, for better and for worse, in considering and adopting new technologies.

One such qualitative research approach is symbolic interaction. According to Herbert Blumer (1969), symbolic interactionism is predicated upon three basic premises: (1) human beings act toward things on the basis of the meanings which these things have for them; (2) the meaning of a thing for a person arises through the process of interaction between people, i.e. through the ways that other people act toward the person with regard to the thing; and (3) 'the use of meanings by an actor occurs through a process of interpretation' (Blumer, 1969, p. 5). Actors decide which objects hold meaning for them and then reform the meanings based on each specific situation. Blumer referred to this as a process of 'self-interaction'. Symbolic interactionism has contributed greatly to sociology by refining self and identity theory, causing us to understand the importance of interaction and situation to the development of self (Sandstrom, Martin, \& Fine, 2001). Seeking to advance their contributions to the study of sociology, interactionists have called for research into the way that the self is contained and shaped by organizational cultures (Sandstrom, Martin, \& Fine, 2001). Thus this research will primarily consider the use of wireless handhelds and subsequent fit with self-identity within an organizational context. Accordingly, a study of current organizational culture inherently requires a consideration of the way that employees utilize the technological tools at their disposal. Further, symbolic interactionism is a social constructionist view (Van Maanen, 1979a) which sees reality as created by humans through meaningful activities. This increases the importance of gaining more understanding of individual use and perceptions through ethnographic interviews with individuals within different organizational cultures.

Interpersonal capacities assume that there are clues in each situation guiding an individual's actions. An individual will use temporal frameworks (such as past use of technology), categorization devices (such as how each device fits within the individual's sense of his/her own place in the organizational hierarchy), and interpretive procedures when deciding on a course of action (Van Maanen, 1979b). This derivation of reality can be considered in different ways. For instance, Erving Goffman (1959) created a dramaturgical metaphor of the self as an actor managing impressions through deliberate actions, which would suggest that employees may use wireless devices as a tool to further manage impressions. Goffman's ideas were extended by Bolino (1999), who suggested that impression management concerns motivated individuals to engage in citizenship behaviors that corresponded with the expectations of the influential target, directed in a way most valued by target and which were noticed by an audience of influential targets. However, when individuals were concerned with impression management, he proposed that their performance would be negatively affected.

In contrast, Van Maanen (1979b) disputes this self-absorbed and cynical look by considering how one's responsiveness to others will guide an individual's actions and potentially promote higher ideals (e.g. equality, harmony and trust). Still, devices may be used in a way designed to protect individuals' views of themselves, or their view of how others perceive them (the looking glass self: Cooley, 1902). In trying to ascertain motive however, we transgress from symbolic interactionist methodology. The question should not be 'why' an individual decides upon a course of action, but rather, 'how' the action 
is undertaken. Interactionist methodology strives to comprehend meaning through actual actions surrounding the use of technology, rather than through a participant's deliberate and analytical self-review.

Use takes place within different contexts. As individuals strive to act appropriately, Van Maanen (1979b) further suggests that they will adhere to different rules of conduct, ranging from formal (which are less psychologically binding) to rules set by culture, by the demands of the situation itself (and the role the individual is currently playing) and finally by one's own sense of rationality and practicality. Spradley (1979, p. 3) suggested that 'Rather than studying people, ethnography means learning from people.' Thus, working from an interactionist perspective, the present study explores dominant themes in the way that employees use handheld wireless devices and considers ways to learn and improve the fit of the handheld wireless technology. A detailed explanation of the study framework and methodology follows.

\section{Study Framework}

Using insights gleaned from past sociological and technological perspectives, several themes for this study begin to take shape surrounding the use of wireless devices, changing demands on individuals, and preservation of self-identity. Consequently, a qualitative agenda was set, loosely based upon the concept of generic social processes (Prus, 1997), or themes, depicted in Figure 1. I suggest that the self assigns meanings to wireless technology within differing domains of social inclusion, that is, on a continuum where individuals use the technology to develop aspects of their identity both related to and separate from interaction with other people. Thus, we see the devices as promoting the imaged self, while at the same time, attending to the needs of a relational self, adapting to the needs of an integrated self, and coping with periods of isolation. These aspects of the self are situated along the same dimension with each aspect influencing and being influenced by a process of innovation occurring through use.

The conceptual framework, while emerging from the work of previous researchers (e.g. Markus \& Wurf, 1986; Prus, 1997), was also suggested by study data. As participants sought to explain how they used the devices, it became clear that use encompassed both relational aspects, that is, denoting an interaction with others and independent aspects, which are a product of a more solitary and comparative process (Markus \& Wurf, 1986).

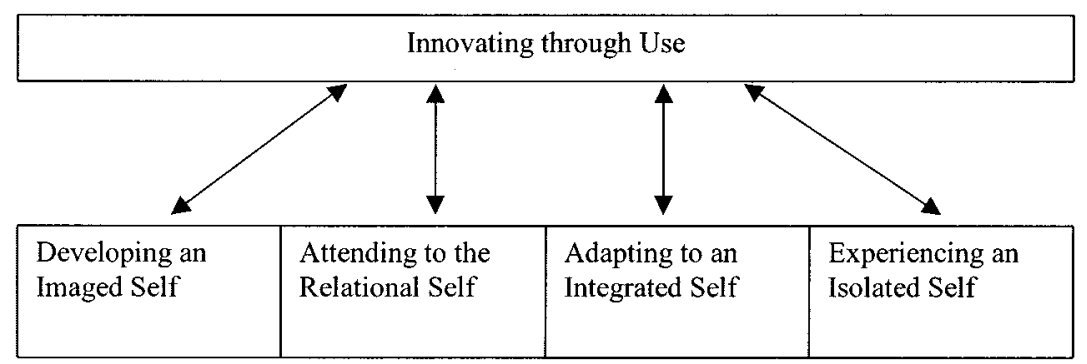

Figure 1. Framework for social processes involved in handheld wireless technology use 


\section{Organizational Context}

\section{Council composition}

A municipal election was underway when this study was conducted. Just prior to the last interviews, the Mayor and the councillor interviewed from Municipality 1 were re-elected. However, the Mayor for municipality 2 was newly elected from a position of councillor, while the other councillors had been re-elected. The last participant had been defeated in the mayoral race and was no longer active on municipality 2 's council when he was interviewed.

\section{Technology choice}

Most of the participants were part of larger groups who had made the decision to purchase the wireless devices for their employees. One of the municipalities studied was in the process of bringing both Clearnet's MIKE and RIM's BlackBerry to the councillors and senior staff. The members of Municipality 1 had been greatly influenced by the experimental nature of their mayor and his test of the device. Municipality 2 had made a joint decision to support a local firm, hoping to benefit from a useful technology. Lastly, one councillor had experienced conflicting interests because he worked for Clearnet, and had retained the use of the MIKE device instead of adopting the BlackBerry. Clearnet later decided to supply his council (Municipality 2) with complimentary MIKE phones, but this happened after completion of the study interviews. The participant from RIM had been given a BlackBerry when she was hired into the company. RIM's policy was to supply each of its employees with a BlackBerry.

\section{Comment}

In short, the organizational context was one in which many employees held positions in both the public and private sector, some simultaneously, and faced multidimensional role demands. Thus, wireless handheld devices held different meanings for each employee, depending on their diverse job needs and backgrounds, and this became problematic for some.

\section{Method}

My interest in the use of these handheld devices began one evening, as I was having dinner with a friend. Although it was 10:30 p.m. and we were in a restaurant, her BlackBerry alerted her to an incoming message. She excused herself from our conversation and, after checking the message, she responded with a short e-mail. When I asked her about it, she noted that it was her boss, and that her boss would expect an immediate reply to the question because it was 'easy to respond to.' Soon after, I read (in the local newspaper) that councillors in two area municipalities had decided to use these devices to be more accessible to their constituents. As I had previously worked in management for one of the municipalities, and was a taxpayer in the other, I decided to approach them to participate in a study of wireless use. They would provide an interesting view of how a diverse set of people, representative of the general population, might use the devices in their jobs. 
Table 1. Participant demographics

\begin{tabular}{llllll}
\hline & Gender & Age range & Interest group & Role & Other occupation \\
\hline 1 & Male & Mid 50's & Public \#1 & Mayor & $\begin{array}{l}\text { Self-employed } \\
\text { Businessman-accountant }\end{array}$ \\
2 & Male & Late 50's & Public \#1 & $\begin{array}{l}\text { General manager } \\
\text { corporate services }\end{array}$ & \\
3 & Female & Late 30's & Private & $\begin{array}{l}\text { Human resource } \\
\text { Project manager }\end{array}$ & \\
4 & Male & Late 40's & Public \#1 & $\begin{array}{l}\text { Director IT } \\
\text { System administrator }\end{array}$ & \\
5 & Male & Mid 30's & Public \#1 & Councillor & Real estate salesperson \\
6 & Female & Late 50's & Public \#1 & Councillor & Salesperson \\
7 & Male & Early 40's & Public \#2 & Costman \\
8 & Male & 40's & Public \#2 & Councillor & Mayor \\
9 & Female & Late 50's & Public \#2 & Councillor & High school teacher \\
10 & Male & Mid 30's & Public \#2 & Fogional councillor \\
11 & Male & Early 60's & Public \#2 & Former councillor & Region \\
\hline
\end{tabular}

\section{Participants}

Eleven participants from two municipalities and from the manufacturer were interviewed. Some held administrative positions within the municipality, some were elected municipal representatives, and one was employed by the manufacturer (RIM) in its Human Resources area. The elected city councillors had backgrounds including an accountant, teacher, letter carrier, insurance agent, and sales representative. Participant ages ranged approximately from their early thirties to early sixties. Seniority within the organization ranged from less than one year to more than 30. A demographic chart is included in Table 1.

\section{Wireless technologies}

Wireless devices can be considered pervasive in nature. Users wear the devices, and are alerted to new messages through a vibration. Called 'unconscious-ware' (Chase, 2000), the device almost becomes a part of the individual wearing it. In this study, two tools are encountered, the BlackBerry (a wireless pager and e-mail device), developed by Research in Motion (RIM), and Clearnet's wireless MIKE cellphone. The main wireless technology studied in this paper, RIM's BlackBerry, incorporates e-mail messaging and scheduling capabilities (www.BlackBerry.net). Embraced by high-profile people in the U.S., its popularity is growing in North America. As noted by Stephen Chase (2000, p. T1): 'Everyone from Al Gore to Microsoft Corp. chairman Bill Gates to movie actor Matt Damon is crazy about the BlackBerry.' Its appeal is based on simplicity, with e-mail its primary function, using a basic black on grey display, with easy thumb-typing, running on a standard AA battery, and carried unobtrusively in a belt holster (Chase, 2000, p. T1). Incoming correspondence on the BlackBerry is limited to selected individuals who have been given the receiver's personal identification number (PIN). This PIN provides the direction to e-mail to send the correspondence directly to the BlackBerry, thus circumventing the organization's main server, while also creating a less secure channel.

The other technology, Clearnet's MIKE (www.clearnet.com), operates more as a cellphone with messaging capabilities. It originated as a two-way radio and has just incorporated e-mail capabilities. On the MIKE, access is controlled through selective phone number distribution. Although convergence of the two technologies seems to be a likely eventuality, they are currently serving mobile 
information interests in different ways. BlackBerries focus on e-mail communication, even though voice messages can be routed through the devices. MIKE specializes in voice messages, and only recently incorporated full e-mail capabilities. Usage has evolved over time. The key appears to be a continuing knowledge of the rapid improvements made to each generation. The technology is still in a technology push stage as opposed to a market pull.

\section{The interview}

Each participant was approached using an explanatory script and was requested to sign a consent form. In this research, I conducted relatively short interviews (1 hour in length), which constrained my ability to examine actual actions. In spite of this, I have tried to focus my interview questions on the 'how' aspect as opposed to the 'why'. Thus, as participants respond, they provide a summary of how they use the devices and what they believe is acceptable technology-practice, rather than a self-review of the 'why' behind the actions. In adopting such a methodology, we attempt to understand how work roles might change with the introduction of handheld devices, based on the experiences of new users and involves asking deeper and customized questions, in person, rather than the use of standardized methods, such as surveys.

The hour face-to-face interview was conducted with each participant and was audiotaped when possible or transcribed while the interview was taking place. In addition, information was volunteered by another individual central to one of the municipalities, which greatly expanded the researcher's understanding of how the technology is perceived by people who interact often with BlackBerry users (but have not been given a BlackBerry for personal use). Individuals were interviewed at a place of their choosing. This resulted in some diversity of location, with interviews taking place in restaurants, City Hall offices, boardrooms and in one case, a councillor's home office. In each case, the interviewee was able to provide a continuous block of time for our interview, resulting in few interruptions. By giving me full attention, I was able to ask and have answered a number of questions, but I was unable to observe participant normal use of the device. Participants were asked to demonstrate features, and to consider the amount and way that they used the devices.

\section{Coding the transcripts into generic social processes}

Both inductive and deductive methodologies were used to code the transcripts. Inductively, an inventory was made of cultural themes, identifying recurring common beliefs and assumptions which related different subsystems of cultural meanings. These themes, or generic social processes (Prus, 1997), were considered in the light of original themes (arrived at deductively from theory and research) and then assembled into this paper. For example, 'attending to the relational self' is a category that would consider the 'processes by which people develop and sustain relationships in actual practice' (Prus, 1997, p. 125) and could be applied to any form of association. This method of using generic processes involves 'attending to the way in which specific people's lives intersect with those of particular others across and within particular subcultural situations' (Prus, 1997, p. 58) and the resulting impact on their involvement. Continual review of the emerging paper by a number of colleagues promoted face validity of the constructs.

The remainder of this paper proceeds as follows. The following section explores how employees use wireless devices, with subsequent changes to social relationships and work routines. It also examines participants' views and concerns surrounding current and future developments. The paper concludes by discussing both research and practice implications of the study's findings. 


\section{Results}

Accepting Prus' (1996) premise that actions across various subcultures can be analysed using similar or 'generic' social processes, we can then categorize them more specifically with respect to the activities involved in the use of wireless devices. These activities are based upon current and potential technological issues.

\section{Innovating through use}

Prus and Mitchell (2000, p. 10-submitted) stated that 'Technology does not adhere in particular objects but, rather, objects acquire technological essence only when specific people envision, approach, or otherwise act toward those items as a means of accomplishing something.' This implies that although the devices themselves (the BlackBerries, MIKEs and substitutes) are continually evolving, this will not constitute technological innovation in itself. Rather, it is the actual use that people put them to which will determine if they are truly innovative. Similarly, Willoughby (1990) developed an 'appropriate technology' framework encompassing innovation and fit within technology practice.

Reflecting upon the nature of technology, it is important to distinguish between technology and technology-practice. Technology is defined by Willoughby (1990, p. 39) as 'the ensemble of artefacts intended to function as a relatively efficient means.' This definition encompasses both the knowledge surrounding a technological tool, as well as the physical hardware and software. In contrast, technology-practice is defined by Willoughby $(1990$, p. 44) as 'the ensemble of operations, activities, situations or phenomena which involve technology to a significant extent.' Within the current study, technology-practice relating to handheld wireless technology is explored. Understanding the 'appropriateness', or fit, of the wireless technology is important to creating positive value from its use in the workplace. Thus technology does not determine its own trajectory of development and use but rather we discover that people themselves create and innovate. ${ }^{1}$

It follows from this line of thought that we need to find out more about how people use technology, so that we can begin to determine both positive and negative outcomes of its use. The social construction of technology (Pinch \& Bijker, 1987) approach considers issues surrounding the propogation of certain technologies, specifically asking the question: Why do some variants of artefacts survive and others do not? Finding its root in social constructivist interactionism, the social construction of technology approach discusses how social groups at various stages in the introduction and implementation of the technology play an important part in determining which issues are important enough to resolve or to discard. Similarly, Saga and Zmud (1994) proposed a causality in the way that people adopt and use technology which influences the implementation and success of technologies.

The shaping of technology-practice is influenced by users as well as designers. Technology development can be considered within a technological frame which 'comprises all elements that influence the interactions within relevant social groups and lead to the attributions of meanings to technical artefacts - and thus to constituting technology' (Bijker, 1995, p. 123). Within this analytical framework, he advances elements of both design (such as testing procedures, design methods and criteria) and use (such as users' practice). Thus, this study's investigation of the way that technology artefacts were used is important to assigning a meaning to wireless technology.

Willoughby suggested that technology practice can be seen in the light of socio-political, ethicalpersonal and technical-empirical dimensions. The technical-empirical dimension considers the technology from a tangible and objective view, that is, as an artefact. For instance, a recent report by

\footnotetext{
${ }^{1}$ Special acknowledgement to Dr R. Gephart for this suggestion.
} 
Goldman Sachs (Mehta, Das, Jones, Mattio, \& Chopra, 2001) surveyed 175 laptop users who were given wireless handheld devices. Forty-five per cent of these users reduced laptop usage, with 19 per cent discontinuing use altogether. The report concluded that the laptops had been used primarily for e-mail, and when wireless handhelds were introduced, became redundant. In this way we see an evolution in innovation, where one technology is discarded by an interest group as different meanings are assigned and interpreted to it and a new device is more 'appropriate.' Socio-political aspects include the 'strategic action of classes of people; social institutions; organizations; and structures which form the main fabric of human corporate life' (Willoughby, 1990, p. 267). Finally, technology practice considers the ethical-personal dimension as being subjective, reliant on past experience and capacity for control and power. Innovating through use considers technology practice from each of these dimensions. Patterns of use varied among interviewees, depending upon their comfort level with technology, and upon the device model they carried.

\section{Managing the volume of communication}

All of the interviewees used the device primarily for sending and receiving e-mails, with more than half experiencing an e-mail volume exceeding 20 e-mails per day. Many participants did not appear to experience a higher load of e-mails due solely to the introduction of the BlackBerry, although technology advances in general could be seen as changing the way people work. From a technical-empirical perspective, the innovation of the wireless handheld in itself was perhaps a later artefact, in terms of electronic technology in general. As e-mail became a more common way to communicate at work, it then prompted the development of appropriate technology which would fit into this new frame of communication needs. In the words of one of the most experienced employees:

'No, I don't believe our e-mails have increased because of the BlackBerry, I believe that it's the way we do business at the City, where virtually every employee has a computer at their desk, and everybody has access to e-mail. It's a way of doing business. It's quite different from the way it was 4 or 5 years ago and you don't even have the paper flow that you had at one time. If I had to do my job the way I did 6 or 7 years ago, I'd be working 16 or 18 hour days. With the technology that we have today-all that we have access to; there's no question, I believe we're much more productive.'

\section{Considering physical aspects of portables and their use}

Appropriate technology issues (Willoughby, 1990) also arose when I interviewed female participants. The technology was not used in the same way, because it did not fit with their mode of dress, that is, it encountered cultural constraints (thus originating from a socio-political domain), which then impeded its use. Most wore the device in the holster on their belts. However, all three women interviewed experienced frustration with its wearability, resulting in two females rarely wearing it.

\section{Relating handhelds to other technology}

Technology practice also took on an ethical-personal dimension (Willoughby, 1990), as participants drew on past experiences in determining the fit of the technology. The wireless handheld was compared with other communication media participants experienced, and use was considered in the light of ethically acceptable behaviors. For example, one participant noted:

(Temporal framework) 'The BB takes less steps than the phone. By the time I pick up the phone and say 'hello,' I can send a one word answer. It's the handiest thing.'

(Ethics) 'Some drawbacks are the safety reasons. Now I drive dangerously-all of us do-on the cell phone and pager, with no hands on the steering wheel.' 


\section{Developing an imaged self}

Blumer $(1969$, p. 15) suggested that the 'self is an emergent, reflective process that is not only to be understood within a community of interacting others, but that achieves its central existence in situated activity.' This situated activity is more specifically described by Prus (1997), who discussed how people attempt to foster consequential self-image through ownership, expertise, and relationships. The achievement of an imaged self (Prus, 1997) can be gained through the use of impression management tactics (Goffman, 1959). In order to promote self-image, people develop proficiencies in using technologies, and learn to manage both relational and isolated aspects of self (Prus, 1997).

Similar to the emphasis placed on social interaction by symbolic interactionists, Fulk (1993) found that work group social influences strongly predicted electronic media use when individuals were highly attracted to their work groups. These social influences also shaped an individual's imaged self, as an individual manages impressions while seeking to be connected to the work group.

\section{Presenting the organization as leading edge}

When analysing the data, image factored into the adoption of the technology. Each municipality wanted to achieve a certain image by adopting the BlackBerry. The mayors of each municipality describe how municipalities 1 and 2 came to use the device:

Municipality 1: 'Municipality 1 was the first in the Region to use the BlackBerry (and Palm Pilot before that). Changing - the pace of technology change wouldn't be that long. I was waiting for the right moment to cross over. And that's what I did, I started working on this Beta. The Palm Pilot was no longer the 'sexy thing,' it was the communications side of it and just during the past year, all council got on. We are the first to experiment with new technology.'

Municipality 2: 'It was on our wish list. What pushed us into it was when Mike Lazaridis announced the Perimeter Institute. It looked embarassing that we weren't doing anything to support them.'

Although both reasons have a strong focus on image, the mayor of Municipality 2 described a less technological and competitive reason than Municipality 1 (who discussed being 'the first to experiment'). Instead this mayor discussed one interwoven with political innuendos, that is, the emphasis was on adopting the technology to support local businesses rather than for increased effectiveness. This may have been due to a much more competitive mayoral race in Municipality 2 than 1 . The mayor for Municipality 1 had been re-elected with little competitive threat, whereas the mayor in Municipality 2 had just won a difficult election for the first time.

\section{Associating prestige}

There was a prestige associated with the possession of a BlackBerry in each of the municipalities which made it desirable for individuals to have one. At both municipalities studied, an employee could only obtain a BlackBerry through a highly controlled process. Only senior employees and those on call were provided with these devices. Senior level employees received it without having to justify its use, likely based more on their profile within the community and ability to foster a high-tech image for the municipality. Less senior employees were not given a BlackBerry unless they could justify it through the requirements of their jobs. A desire to be a part of the senior 'in-group' with its perks and prestige may have expressed itself through a desire to have this, the newest gadget. A user discussed this demand:

'Great acceptance level here. Everyone requesting it-but don't get it-it has to go through certain approval steps. I got it for my on-call. It's like the cellphone used to be-it's hard. Everyone wants the toys - sure they can come up with 10 reasons why they need it-but do they need it?' 
Some councillors experienced ambivalent attitudes toward BlackBerry use while visiting with poorer constituents or when participating in televised city council meetings. This was also a form of image management, as councillors considered the image they projected to voters. For example, one councillor noted:

'Often I notice the people I'm dealing with in a neighbourhood association-where people can't even afford a phone-it wouldn't be appropriate to just flip this out.'

'If (e-mails are) buzzing around (at televised Council meetings) and all of a sudden a joke appears and half the Council bursts into laughter during a serious presentation-the public doesn't like that.'

\section{Developing etiquette}

A desire to conform to social rules of etiquette also preserves an individual's image. Most people perceived it as rude if they were having a face-to-face conversation with someone who was simultaneously checking a pager. This occurred in larger meetings, where people sought to escape boredom of a meeting with other wireless users who shared their disaffectation with the main meeting. For instance one such meeting attendee commented:

'Rather funny - go in certain groups now, you're all checking schedules or someone has a message coming in. It can be distracting but you have to deal with it rather discretely-below the desk, people don't see it. It's not as invasive.'

This was a diversion as well as a covert tactic used to conduct communication on a more exclusionary level. It was used to promote a sense of solidarity by excluding people without devices, or who shared a differing view as to the appropriateness of the subdialogue. On an individual level, it was more apparent to users who were not a part of the conversation, as the pager disturbed and took priority over their own conversations.

'Wouldn't be a problem if people would learn a little etiquette with pagers. Some are obnoxious, taking intrusive messages and sending notes.'

Sometimes people sought to find socially acceptable excuses for the conduct, like 'he's a very busy man' or 'I'm on call.' They often related opinions of other people who lived outside the wireless subculture as examples of social support in their own condemnation of this behavior. For example,

'I leave it on all the time. I keep it in my purse. I check it when I have time. Some of the men, they're vibrating all of the time. Years ago, I had to stop being interrupted. It got to the point, where I couldn't stand it-every 10 seconds. I think it's rude and ignorant if people read while talking to you. People find that rude and ignorant. The person that's with me is more important than the one on the phone. This can be very disturbing. I was sitting with J., the President of C. C., and he was absolutely furious that someone at City Hall would continue to do this [respond to pager] while sitting with him.'

'I can do more than one thing at a time-but most people get furious when they see that [other people doing more than one thing at a time] and don't understand.'

\section{Safeguarding image}

Impression management was also a factor in some individuals' decisions to use two separate planning tools to separate personal information from business-related information. Although this was raised in 
the context of safeguarding privacy, employee concern regarding information contained on the handheld also became a way to safeguard image. For example, one participant noted:

'I don't use a paper planner. I still have a filofax/daytimer that I use for personal stuff. I'm getting more and more comfortable putting more stuff on this. They (employer) have access to the info on it-not sure if I want them to know personal life. When you delete-it's still on the server somewhere.'

'I don't put anything in it that I don't want them to see. If there is anything personal, I don't save it.'

\section{Attending to the relational self}

The current study explores how individual participants have appropriated and fit the wireless device into their own lives and how their relationships may change through its use. In the past, Adaptive Structuration Theory (DeSanctis \& Poole, 1994) considered the way that new technologies were adapted through a gradual appropriation of technology, task and organizational environment structures, and group structures, further influencing decision processes and outcomes. This adaptation process suggested that structural considerations in the group, task and organizational environment would be more likely to change throughout the process. Accompanying changes in the group, task and environment, Yates, Orlikowski, and Okamura (1999) found that social interaction within communities was changed and yet also reinforced while adapting to new electronic communication technology.

Describing man as a 'social animal,' Prus (1997) discussed the relational self as the desire for and the openness to affiliation. According to Blumer (1969), social psychology rests on the premise that individual experience takes place within a group life setting, which exerts a decisive influence on the individual. It 'rests on the fact of human association' (Blumer, 1969). Human association sounds relatively passive, but it is the individual's desire to be a part of this group driving the connection. While facilitating communication between individuals and groups, these devices also increase the user's feelings of accountability to other parties. This makes it necessary for people to make decisions as to the terms of their relationships and the technology mediating them.

Prus (1997, p. 174) discussed people's sense of belongingness and how it leads to a sense of integration in their relationships. Rather than speaking in generalities, Prus suggested that this isolation or affiliation should be measured relative to a set of associations and their 'situated self.' Mutuality is a sort of integration, which is fostered by interactive technologies, such as the BlackBerry, which permit access to chosen others, and strengthen their ties. This mutuality can be fostered by the use of humour between people and chosen others, as noted by Prus (1997) in a footnote citing Yoels and Clair (1995). This same use of humour may serve to disaffiliate users if not managed relative to the objectives and priorities of the setting (Bjorklund, 1985).

In developing the related self, an individual will go through a process of 'enabling,' where (s)he begins to feel greater control over his(her) actions. For instance, a number of lawfirms have recently purchased BlackBerries for their staff. One lawyer commented that considering the wireless device a competitive advantage, he even checked his e-mail between drillings and fillings at the dentist (Schwartz, 2001). Thus, a related self would include the satisfaction attached to being reachable and being able to reach others when needed.

\section{Having fun (alternatively)}

For many participants, the desire for mutuality inherent in the relational self took on a diversionary form, and often involved the use of humour. Secondary electronic meetings would operate in the 
background of the primary meeting. For instance, participants from both municipalities, within council and administration, discussed using the device in this way:

'A couple of councillors will send messages back and forth in a meeting or if they aren't in the same place-how can I put this - with some information-or bits of gossip ...that we wouldn't have done before. It's the kind of thing that adds to relationships.'

'I mainly use it in meetings. Switch off what's going on (in the meeting) and go to pager. Able to excuse myself from what's going on. I communicate with other persons in the meeting-all the time-especially if it's a boring meeting-use it for other work purposes-covering topics not in the meeting.'

'I use my BlackBerry in meetings - it can be a curse, you can hear it when it vibrates, especially in Management meetings. You try not to be too intrusive - more subtle to use. In a meeting, you let it vibrate, don't answer. In a long meeting you kind of want to answer it. Sometimes I'll send messages to people at a Council meeting - if I'm watching it on Rogers (cable television)—if the question is related (to my area). Mostly I would send to P. and G. (senior administrators).'

'Other things I like are at Council meetings, they can be a little boring, I can send a message to another councillor and ask 'What do you think?' It adds to the interplay in committee meetings. It's very small and easy to carry. It provides instant access to people.'

Humour would often factor into the use of the devices within these secondary electronic meetings. Most participants used the handheld to introduce humour during a boring primary meeting. However, each person had different and conflicting interpretations of this technology-practice. For instance, the two people below had differing views on the acceptability of sending jokes during council meetings, which influenced the mutuality inherent in the primary meeting.

'Sometimes we'll (councillors) send a message across Chambers. It'll wake you up. Once during a long meeting, there was a joke and three of us started to laugh.'

'I also get resentful when I'm sitting in meetings ... BlackBerry each other through serious discussions with citizens. I don't appreciate that. We owe it to our constituents to listen. It's demeaning to people who make presentations.'

\section{Relating en route}

As people tried to cope with high communication demands, the wireless handheld made it easier to continue to do their jobs as they travel away from the office. Regardless of age, use of the device caused participants to feel more accessible and affiliated. For instance, two senior administrators from Municipality 1 noted:

'I recently went to Ottawa, and while I was not driving - I had someone driving with me -I spent the greater part of the afternoon responding to e-mails. When I arrived in Ottawa I entered my hotel room where I had also received my e-mails and by 5:30 or 6:00 I was done with my e-mail. I had done that all while I was 400 miles away. I also receive e-mail like that on the weekend. I don't think I could have coped with the added responsibility that I had during the 6 months I was acting GM.'

'I feel in control-my managers can always reach me. They know how to get a hold of me within 5 minutes to address issues.' 


\section{Becoming more 'reachable'}

There were instances where people encouraged others to get a BlackBerry to increase communication with them. For example, these two individuals discussed both work-related and personal relationships:

There was one councillor who had no interest in e-mail whatsoever, and the staff here are predominantly e-mail. Got him a pager. He liked it. For the first time I could now get a hold of him.

I wish my husband would want one... I haven't figured out a way to communicate with him through the day.

\section{Adapting to an integrated self}

The emergence of wireless communication and subsequent introduction of mobile wireless devices are changing the ways in which people organize their work and personal lives. Internet-enabled handheld computers incorporate features which suggest further blurring of the traditional family-work boundaries. This pervasiveness, manifested by its wearability, within an 'always on' context may create expectations to be on call 24 hours a day, seven days a week. If an employee receives an e-mail, and is expected to be on-call, then the speed of response will confirm the person's true availability. This then becomes a criterion for recognition through its 'high visibility' (Perlow, 1997, p. 34). Individuals may encounter the same work-family conflicts detailed in Perlow's (1997) ethnography, Finding Time. In that study, engineers who made sacrifices at work for home were more stressed than others who placed a higher priority on work because they were more aware of the competing demands of home and work. Similarly, Parasuraman and Simmers (2001) studied the double-edged sword of autonomy and flexibility resulting in higher work-family conflict and lower family satisfaction. Consequently, the study focuses upon the way that individuals regulate the boundaries between work and family life while using wireless handheld devices.

\section{Changing work contexts}

Participants found that attending to relational needs often slipped into a grey area, and required changes to their work and personal roles as they adapted to integration between work and personal roles. The technical capabilities of the technological artefact increased the amount of work-related communication during personal time, but also sped up the process of addressing these demands.

'It's a communication tool-people who haven't been able to get ahold of me, now can'til midnight. I've received messages as early as 5:45 a.m. and 11:30 p.m. The number of messages per day varies. Maybe a dozen? Mine have increased since I got the BlackBerry. N. (my assistant) talks to me two or three times per day.'

'I wear it all the time. Leave it on at night and, place it on the bed stand-same with T. and F. It's in their job description that they need to be available 7/24 [7 days per week, 24 hours per day]. I look at it when it rings and make a determination of who it is. The CAO keeps odd hours, goes through mail, or it might be T. or F.-looking for problems somewhere.'

Each person had fit its usage into their own life-pattern which reflected some division between work and personal life. For instance all 11 participants acquired it as a business tool, and only three said that they also used it for personal use. Some used the technology as a backup to current information systems. For councillors, the BlackBerry spilled over into their day jobs, blurring the line between specific job duties attached to specific roles. Some experienced difficulties in trying to use the device to integrate their multiple work roles. For instance, two councillors remarked: 
'It's difficult with my job as a postman to stop and respond.'

'I keep it on in the classroom. I leave it on the desk or in my pocket or briefcase. At lunch I'll check e-mails. I don't really pay attention to it. I don't wear it on my belt. When I'm teaching, I'm not really allowed to have it on. All the kids have pagers and cellphones. But technically it's not allowed.'

\section{Increasing expectations of availability}

Participants experienced increased expectations of employee availability. For example, a long-term senior administrator commented:

'Personally, I have not found that the technology has added more stress, but the articles that I have read have suggested that, yes, the electronic age in which we're working have added to the stress levels. And I think the expectations of the employer of employee have been greater because of the technology. I'm not saying that technology that we're using today is not good for everyone.'

\section{Setting limits}

Others tried to be open to the people who correspond with them, but regulated who it was that they were actually serving with this communication tool. In this way the individual begins to set conditions upon fulfilling others' expectations of his/her availability. They may have regulated this through selective distribution of their personal identification number, or just through the way that they selectively read and respond to certain messages that came to them via the BlackBerry. For example, these four participants all had differing ways of regulating, while still trying to maintain approachability.

'I get 30-50 messages/day in the morning when I check. Probably 10 per cent of these are things that really concern me. The staff like to think you're interested in everything. Some things it's better to wait and read in written form.'

'J. made the mistake of saying during a radio interview with CHYM, that she would give her PIN to everyone. I think the answering machine is enough for the constituents to get you-otherwise they'll call you in the middle of the night.'

'Having the computer hooked up to the Internet, constituents are e-mailing a lot more. The BlackBerry PIN isn't given out to everyone. We don't want SPAM on the BlackBerry.'

[Would they send them if they knew it would bother you?] 'I don't think that's the issue-I have a choice. I know that J. has said that once in a while a councillor will e-mail him with a question at 1 a.m. in the morning., and he works until 2 a.m. or 2:30 a.m. often, so he can answer it and the answer is waiting for the councillor when the councillor wakes up in the morning.'

Just as Perlow (1997) noted in her book Finding Time, forced quiet time in hectic 'always on' schedules increased the quality of workplace relationships and even productivity. For the following participants in this study, it became an issue to ensure that time for revitalization was not interrupted.

'At night I usually put it on my dresser-it's still activated. The only time I don't wear it is Sunday. Really the only thing I have on on Sunday is my regular pager, as a back-up to reach me at home [this participant is on call 24 hours per day, 7 days a week through his regular non-RIM pager]. Second of all, I don't want the BlackBerry to ring at Church.'

'I balked at the cellphone, I thought it interfered with my privacy. Don't have a lot of privacy in my job. I could listen to music on the way, and arrive serene. Cellphone calls interfere with my privacy.' 
'Never owned a mobile phone or pager. Had made a personal choice not to have it-found it intrusive. If I'm not there, then they have the answering machine.'

'It interrupts everything_lunch and dinner. I'll take a quick look and put it back_prioritize responses.'

\section{Getting hooked on the devices}

Disaffectation with the device may occur through a power struggle for control. Prus (1997, p. 61) discussed how people become disinvolved in a subculture when they find activities troublesome, and encounter emotional difficulties. Similarly a recent report by the Canadian Policy Research Networks (Lowe \& Schellenberg, 2001) concluded that employees in weak employment relationships desire better communication, fairness and respect, recognition, and a more supportive work environment. However, even though the premise of 'enabling' (discussed earlier) implies heightened control over one's actions by granting increased communication ability, the device, designed to be worn continuously on an individual's body, constitutes an open medium of communication, and it may begin to set conditions on the user's life. For instance, Chase (2000, p. T1) wrote: 'RIM's wireless e-mail device generates its own vocabulary as road warriors get hooked on its addictive simplicity.' Therefore, the concept of an integrated self may be influenced by findings surrounding the issue of technological engrossment or 'flow.' 'Flow' is best described by Csikszentmihalyi (1975, p. 182) who concluded in a study of autotelic activities, that:

'... when people enjoy what they are doing, they enter a state of flow: they concentrate their attention on a limited stimulus field, forget personal problems, lose their sense of time and of themselves, feel competent and in control, and have a sense of harmony and union with their surroundings. To the extent that these elements of experience are present, a person enjoys what he or she is doing and ceases to worry about whether the activity will be productive and whether it will be rewarded.'

Since participants in this study generally wore their wireless devices throughout most of their work duties, it was pertinent to investigate whether participants experience a state of flow while using their devices. For instance, this high tech user exhibited substantial engrossment:

'I've received 36 e-mails so far this morning [this is a lunch interview]. The phone comes straight to the pager too. Can't listen to message but I know that someone has called. I received 52 e-mails yesterday between 8:00 a.m. and 11:00 p.m. The last one was at 11:27 p.m. The first one was at 1:00 a.m. The next 5:20, 6:00, 7:00 a.m. I get woken up by this. Now I keep it away from the bed. When you first get them (pagers), you're excited.'

'I don't let it control me. That's the difference I've seen in the younger people at work. They let it control them-they never take it off. Sometimes $V$. and I have to be careful-we get so engrossed in it at home-even with each other, that the kids notice. ${ }^{2}$

However, 'flow' did not appear to be present for most users. Even the users who demonstrated engrossment, did not use words signifying enjoyment as they described the way that they used the BlackBerry. For example, the high tech user above also noted:

'People continuously check it. I would recommend 3-4 times per day but the black line (indicating messages) is bothersome. If not careful it can rule your day, which you don't want it to do. Forms part of the 'to do' list but didn't plan for it. At the end of the day, when look at the paper on your desk, you wonder what you've done all day-you've dealt with e-mails.'

\footnotetext{
${ }^{2}$ Later this user increased the inclusiveness of the technology by purchasing BlackBerries for her children.
} 


\section{Experiencing an isolated self}

Prus (1997) suggested that individuals feel isolated when they are unable to realize a desired mutuality. Users, in their attempts to fit the BlackBerry into their lives, could experience a feeling of isolation if they are unable to access their device when they need to. There is some reliance upon the technology to make them feel a part of the organizational subculture. Addressing feelings of isolation while adapting to the 'integrated self' and developing a 'relational self' may cause conflicting choices in personal use of the handheld. Technology-practice then, may be influenced by socio-cultural aspects, as interpreted by the individual.

\section{Minimizing isolation}

These four participants discussed their dependence on the device and the frustration that occurred when they were unable to access it:

(Out of the country) 'I used it for notes-clip notes - I use it for schedules, for my address book, I used it for a planner - calling back home. It was with me even though I wasn't able to use its e-mail.'

'My parents came over in the summer. I took my pager with me to Niagara Falls for two reasons. V. and I can keep in touch. I also received an urgent e-mail from someone in London, England, and I was able to deal with it in half an hour. Most people will say 'away from desk, but still connected by pager', and will check periodically on their voicemail.'

'We couldn't do without them now. One of the councillors isn't running again for council, and wanted to transfer the unit to himself personally, but we couldn't allow that. He even wanted to purchase it but he'll have to purchase his own.'

'I had to hand in my BlackBerry [a different councillor who was unsuccessful in the municipal mayoral elections]. I'm going to buy another one. It gives me instant access to people.'

\section{Results summary}

Table 2 highlights and summarizes salient interview results and provides a better understanding of the relative importance of each social process by noting its frequency. Thus, we can note that the appropriateness of the technology for women was strongly influenced by something as basic as the wearability of the device. The table also suggests that a shared etiquette was evolving, including five of the 11 participants. Relationships also developed, as all of the participants discussed changes in availability and expectations of availability. Most set up routines to regulate these expectations, but felt uncomfortable when they perceived themselves to be unavailable.

\section{Discussion}

The current research contributes insights into the actual uses of technology in organizational behavior, in particular, by providing a closer look at the way that individuals in organizations perceive and use handheld wireless devices.

Focusing on aspects of the self, we gain a clearer understanding of how individuals interact with technology, and indeed, how it was used to complement their personae. Thus, we can first consider 
Table 2. Results

\begin{tabular}{|c|c|}
\hline Social process & Responses \\
\hline Innovating through use & $\begin{array}{l}\text { - Each participant was able to give examples showing that they had } \\
\text { adapted to using the device } \\
\text { - All three women interviewed expressed concern with the device's } \\
\text { wearability. One man also expressed concern in this context, after } \\
\text { mentioning his wife's preferences }\end{array}$ \\
\hline Achieving the imaged self & $\begin{array}{l}\text { - Three participants discussed the image of their municipality in the } \\
\text { context of being 'first' with technology } \\
\text { - Both municipalities used a prestige-based allocation methodology when } \\
\text { providing employees with a handheld } \\
\text { - Five subjects consider it poor etiquette to interrupt face-to-face } \\
\text { conversations with wireless devices. This excluded and distracted } \\
\text { face-to-face communication partners }\end{array}$ \\
\hline Attending to the relational self & $\begin{array}{l}\text { - Each participant noted the emergence of secondary electronic groups } \\
\text { operating in the background of primary meetings } \\
\text { - Six participants discussed satisfaction that they are now available to co- } \\
\text { workers who need to reach them } \\
\text { - All } 11 \text { users discussed the desire of others to reach them, and the pitfalls } \\
\text { and benefits associated with increasing one's availability (i.e. pitfalls: } \\
\text { SPAM, being on too many distribution lists, late night messages) } \\
\text { - Eight respondents discussed their ability to reach co-workers who were } \\
\text { previously difficult to reach }\end{array}$ \\
\hline Adapting to an integrated self & $\begin{array}{l}\text { - Eight users discussed how they set up various routines to regulate their } \\
\text { work and personal lives using the device } \\
\text { - Four others discussed the challenges of protecting personal time with a } \\
\text { pervasive technology } \\
\text { - Five users discussed how they regulated their use of the device to avoid } \\
\text { becoming 'hooked', but only two exhibited significant signs of } \\
\text { engrossment }\end{array}$ \\
\hline Experiencing an isolated self & $\begin{array}{l}\text { - Six users did not feel comfortable when their communication using the } \\
\text { wireless device was interrupted. This could happen as a simple service } \\
\text { coverage problem, or more of a psychological effect during a vacation or } \\
\text { after severance }\end{array}$ \\
\hline
\end{tabular}

how participants projected desired self-image as they interacted with constituents and co-workers. Further, they experienced relational desires, most importantly the desire for mutuality, which assumed a conflictual nature when each party interpreted wireless technology practices differently. The adaptation to an integrated self incorporated a need to balance both work and personal lives. This required participants to self-regulate their use of the handheld and to 'redraw' the lines between work and family time, sometimes more definitively; other times with a blended stroke. Additionally, coping with isolation, after having been exposed to a high level of connectivity, created turbulence for the isolated self.

Within this study, we can appreciate how these aspects of self are continually in transition, changing as users experiment and fit the new wireless technology into their lives. This reflects a trend toward innovation through use. As users found themselves adapting to the technology, the technology was also adapted to their lives, sparking new and innovative uses and influencing group processes. Thus, we can note the emergence of concerns expresses by Adaptive Structuration Theory, wherein DeSanctis and Poole (1994) suggested that as users appropriate the technology, they change their internal group structures, the task and the organizational environment for a better fit and cause new social structures to 
develop. Continued use encouraged users to adapt their message contexts, social etiquette, selfimpressions, and ways of doing business. As they used the wireless devices, they further refined their perceptions of its technology practice. Orlikowski (2000) also discussed innovation arising out of an individual's awareness of alternative technology practices. This aspect became apparent as participants shared usage of the wireless handhelds with other users through restricted PIN access and learned of new ways to use the devices.

These results suggest that certain influences shape wireless technology-practice and innovation in use. When considering routinization, noted in previous research (Saga \& Zmud, 1994), it was also apparent that different interest groups established different ways to use the devices. Interpretive differences have been explored across interest groups in previous studies including studies of sensemaking practices during a public inquiry into a crisis (Gephart, 1997) and electronic trading implementation in the London Insurance Market (Heracleous \& Barrett, 2001). Interest groups emerge in the current study as we consider the groups of elected and staff administrative employees highlighted in Table 1. Two of three in the administrative group were involved in the information systems area of Municipality 1 and responsible for the introduction of technology to other employees at the city. The councillors were all part-time and held down regular, full-time jobs in addition to being a councillor. The mayors were both full-time. These different backgrounds and needs of each interest group influenced technology-practice (e.g. councillors did not use the device as frequently as the information systems administrative employees).

Participants engaged in technology practices promoting an imaged self. These practices often coincided with organizational citizenship behaviors. For example, the decision to adopt the technology enhanced an image of high technological competence and support for local businesses. However, the device was not used when it was not perceived by the councillors to support a different desired image, as in the case where meetings were held with neighbourhood representatives in poorer areas. This technology practice appeared to support Bolino's (1999) contention that 'on the surface, many impression management strategies are very similar-if not identical—to citizenship behaviors' (Bolino, 1999. p. 83).

'Attending to the relational self' involved interaction with social groups. Similar to aspects of the Social Influence Model of Technology Use (e.g., Fulk, 1993), the influence of important others (such as the mayor of Municipality 1 on the rest of council) played a significant part in the decision to adopt and to continue to use BlackBerries as a communication medium. The influence of social groups on technology practice can also be seen in the way that technology was used, especially when a secondary level of meetings emerged via the device.

Adapting to an integrated self posed interesting time challenges for participants. The overlap of handheld use from work to homelife encouraged participants to try to regulate their responses. ' $24 / 7$ ' is a fairly new term which describes an ancient work condition. Doctors and many other roles have been 'on call' prior to the introduction of wireless technology. However, handhelds have now created a situation where 'on call' has become a pervasive and instantaneous demand. A 'brave' employee must be able to respond to increased expectations of availability within our 'brave new world.'

Few of the participants in this study exhibited extreme behaviors. In fact, because the participants were drawn from a mainstream segment, this may indicate that engrossment may not become an issue for traditional corporations to anticipate and address. However, engrossment was present in the individuals who had professional information systems interests, within the public and the private sectors. It also became an issue where there was a high percentage of personal and work-related peers who had access to BlackBerry communications. However, in most of the interviews, the language that was used by participants did not reflect pleasure in using the device; that is, 'flow' (Czikszentmihalyi, 1975) was not noticeable. 


\section{Contributions}

Applying a symbolic interactionist perspective in this research contributes to organizational behavior research through its pragmatic, 'down-to-earth' look at how employees perceive the technology. Faceto-face interviews foster an openness to discuss subject views that is not invited through quantitative research. It is appropriate to use this type of flexible, subject-responsive research to discover how different types of people in different organizations utilize similar business tools. This provides a new, 'indepth' consideration of users, and one which both academics and practitioners might find useful.

The study contributes by responding to a call by symbolic interactionists for more research into organizational life (Sandstrom, Martin, \& Fine, 2001) and technology practice (Orlikowski, 2000). It contributes to the field of organizational behavior by investigating the use of handheld devices (a 'new' technology to organizational behavior). As Orlikowski (2000) noted, 'what is relevant to both academics and practitioners is the use of the technology not the technology itself'. Thus, as we see new technology practices evolving out of the different meanings that individuals place on wireless handhelds, we will begin to understand how the technology will influence the new workplace. As a study profiling mainstream users, it also provides us with valuable knowledge about the way that nontechnical employees view and use the devices.

Just as this study enhances our knowledge of user behavior with wireless handheld devices, it complements knowledge gained by studies that have centred around system design issues (e.g., Dix et al., 2000). This has become more relevant to companies in general; for example, from a practitioner pointof-view Ossip (2001) discussed the extension of wireless applications to all employees, and the challenges of integrating this technology with both employee and organizational needs. Similarly, Orlikowski (2000) discussed the increasing trend toward interconnectivity as business Internet use becomes the norm. This study shows the need to include system design issues in organizational behavior, and the need to study systems design using an organizational behavior perspective.

\section{Limitations and Suggestions for Future Research}

Potentially, future researchers would find value in a more extended ethnographic study, including a wider range of potential informants. The current study was undertaken during a municipal election, when councillor time was at a premium. Additionally, a participant-observer viewpoint might have resulted in a deeper examination of the human-technology interaction.

The data collected from the 11 individuals, while valuable, would have been more comprehensive if a greater number of participants could have been solicited. The participants were concentrated within an older age group, above 30 years of age. At a time when high-tech gadget adoption and implementation are associated with the age group under 30 years of age, this may have affected the level of technological familiarity and engrossment.

Future research should include more interviews within the private sector. It would be interesting to note if the perception and use of wireless technologies would be different within the private and public sectors. It would also be of benefit to investigate whether age or gender plays a role in the ways that people perceive and use the technology. The current study highlighted a possible gender difference with respect to 'receptivity to others.' The female participants vocalized how they value the opinion and perceptions of their constituents and how this then affected their behaviors during council meetings and in visiting poor neighbourhoods. 
This study of individual use must also be expanded to consider the ways that teams use wireless devices. Many organizations foster a team-based, organic culture in which employee demands for work flexibility and the requirements of doing business globally, combine to create an environment requiring effective remote teamwork. The emergence of secondary electronic groups in this study raises questions as to how teams would effectively use handhelds (currently used more on a dyadic level), both in remote and face-to-face meeting environments.

Additionally, the leader-follower relationship was not fully developed within the current study. Participants were largely self-directed, or worked as a team. Thus, a form of social influence was present, but with no direct authority. Wireless handheld may influence the way that employees interact with their direct supervisors. This further develops our concept of the related self, specifically as the self relates to significant others.

\section{Implications for practice}

Although handheld wireless devices were considered primarily a business tool, this study suggests that individuals will develop unique technology practices arising from their own unique sense of selves. Organizations must be cognizant of how the use of a handheld may require active steps to help employees address work and personal time conflicts. If an employee is expected to be on call 24/7, then this must become a formal part of the job, acknowledged by the employee upon entering the role. It should not be an expectation introduced later, as an unintended by-product of wireless technology capabilities.

However, companies should take steps to retain and foster the innovation accompanying individual interpretation of the device. Employees creatively utilized the capabilities of the handhelds, whether through secondary electronic meetings, use in transit, or increased availability to the organization while occupied in other personal or work roles.

Participants experienced conflicts between the organizational culture and social boundaries, such as when participants addressed work-related messages on the handheld while driving even though they considered this action to be socially unacceptable. This is important to practitioners because it demonstrates the importance of clear policies guiding employees in the appropriate and safe use of handhelds. Other conflicts arise through the use of the device while meeting with other individuals face-to-face. Such interruptions might appear to demean business partners and could influence the organization's public image.

The handheld was considered by most users to facilitate communication. It increased access to e-mail correspondence and e-mail had already become a primary medium of business correspondence. Many users preferred using a handheld to a traditional phone, and as one participant noted, 'I can send a one word answer.' This trend toward brevity might imply increased opportunities for misunderstanding impeding communication and damaging relationships. To ensure effective communication, employees need to appreciate how the media type and richness fit with the message they are trying to communicate as well as understand the ways that communication is affected by each individual corporate culture (Daft \& Lengel, 1987).

In summary, this research underlines how wireless communication technologies are increasingly pervasive and central to the new world of work. It has provided insights into the way that non-technical users at the forefront of wireless technology adoption perceive and use their devices. We can better understand the influence wireless technologies have on mainstream users. Results can be used from an academic viewpoint to develop future research into pervasive and personalized types of technology as well as from a practical organizational viewpoint, to develop better ways to promote effective technology usage. Finally, we can conclude that the proliferation and use of wireless technology influences 
organizational processes and practices. This paper demonstrates the need for, as well as an approach to, incorporating technology within the domain of organizational behavior.

\section{Acknowledgements}

I would like to acknowledge my indebtedness to a number of individuals. I would like to thank Dr Doug Brown, Dr Robert Gephart, Dr Robert Prus, Dr David Zweig, and two anonymous reviewers for their kind assistance in reviewing this paper. Special thanks to Dr Jane Webster for her assistance, input and continued support of this paper.

\section{Author biography}

Francine K. Schlosser is a PhD Candidate in Management Sciences at the University of Waterloo, having returned to academia after working in industry for a number of years. She is currently conducting further behavioral studies of wireless technology use, the leader-follower relationship and entrepreneurship.

\section{References}

Bijker WE. 1995. Of Bicycles, Bakelites, and Bulbs: Toward a Theory of Sociotechnical Change. The MIT Press: Cambridge, MA.

Bjorklund D. 1985. Dignified joking: humor and demeanor in a public speaking club. Symbolic Interaction 8: 33-46.

Blumer H. 1969. Symbolic Interactionism: Perspective and Method. Prentice-Hall: Englewood Cliffs, NJ.

Bolino MC. 1999. Citizenship and impression management: good soldiers or good actors? Academy of Management Review 24: 82-98.

Chase S. 2000. BlackBerry season. The Globe and Mail. (Toronto), 14 December, T1.

Cooley CH. 1902. Human Nature and the Social Order. Scribner's: New York.

Csikszentmihalyi M. 1975. Beyond Boredom and Anxiety. Jossey-Bass Publishers: San Francisco.

Daft RL, Lengel RH. 1984. Information richness: a new approach to managerial behavior and organizational design. In Research in Organizational Behavior (Vol. 6), Staw BM, Cummings LL (eds). JAI Press: Greenwich, CT.

DeSanctis G, Poole M. 1994. Capturing the complexity in advanced technology use: adaptive structuration theory. Organization Science 5: 121-147.

Dix A, Rodden T, Davies N, Trevor J, Friday A, Palfreyman K. 2000. Exploiting space and location as a design framework for interactive mobile systems. ACM Transactions on Computer-Human Interaction 7: $285-321$.

Eadie A. 2001. How wireless connects in North America. The Globe and Mail. (Toronto), 9 January: T2.

Fulk J. 1993. Social construction of communication technology. Academy of Management Journal 36: 921-950.

Gephart R. 1997. Hazardous measures: an interpretive textual analysis of quantitative sensemaking during crises. Journal of Organizational Behavior 18(S1): 583-622.

Goffman E. 1959. The Presentation of Self in Everyday Life. Doubleday \& Company: New York.

Heracleous L, Barrett M. 2001. Organizational change as discourse: communicative actions and deep structures in the context of information technology implementation. Academy of Management Journal 44: 755-778. 
Lowe GS, Schellenberg G. 2001. What's a good job? The importance of employment relationships. Canadian Policy Research Networks. Renouf Publishing Co. Ltd.: Ottawa, ON. http://www.cprn.org/Release/Other/ pwgj_e.htm.

Markus H, Wurf E. 1986. The dynamic self-concept: a social psychological perspective. Annual Review of Psychology 3: 299-337.

Mehta V, Das R, Jones JM, Mattio DJ, Chopra SP. 2001. Research in Motion Ltd. (RIMM) Technology: Mobile Internet. Goldman Sachs Global Equity Research, April 6, 2001. New York.

Orlikowski WJ. 2000. Using technology and constituting structures: a practice lens for studying technology in organizations. Organization Science 11: 404-428.

Orlikowski WJ, Iacono CS. 2001. Research commentary: desperately seeking the 'IT' in IT research-A call to theorizing the IT artifact. Information Systems Research 12: 121-134.

Ossip D. 2001. Into the plant and onto the road: extending wireless applications to all employees. HRProfessional, October/November, 54.

Palen L, Salsman M, Youngs E. 2000. Going wireless: behavior and practice of new mobile phone users. ACM Conference on Computer Supported Cooperative Work, December 2-6 (pp. 201-210). ACM: Philadelphia, PA.

Parasuraman S, Simmers CA. 2001. Type of employment, work-family conflict and well-being: a comparative study. Journal of Organizational Behavior 22: 551-568.

Perlow LA. 1997. Finding Time. ILR Press: Ithaca, NY.

Pinch TJ, Bijker WE. 1987. The social construction of facts and artefacts: or how the sociology of science and the sociology of technology might benefit each other. In The Social Construction of Technological Systems, Bijker WE, Hughes TP, Pinch TJ (eds). The MIT Press: Cambridge, MA.

Prus R. 1996. Symbolic Interaction and Ethnographic Research. State University of New York Press: Albany.

Prus R. 1997. Subcultural Mosaics and Intersubjective Realities. State University of New York Press: Albany.

Rybczynski W. 1983. Taming the Tiger. The Viking Press: New York.

Saga VL, Zmud RW. 1994. The nature and determinants of IT acceptance, routinization, and infusion. In Diffusion, Transfer and Implementation of Information Technology, Levine L (ed.). Elsevier Science B. V.: North-Holland.

Sandstrom KL, Martin DD, Fine GA. 2001. Symbolic interactionism at the end of the century. In The Handbook of Social Theory, Ritzer G, Smart B (eds). Sage Publications Ltd: Thousand Oaks, CA.

Schwartz E. 2001. Mobile's day in court. Infoworld, July 23, 52.

Spradley JP. 1979. The Ethnographic Interview. Holt, Rinehart and Winston: New York.

Taylor S, Todd PA. 1995. Understanding information technology usage: a test of competing models. Information Systems Research 6: 144-176.

Van Maanen J. 1979a. On the understanding of interpersonal relations. In Essays in Interpersonal Dynamics, Bennis W, Van Maanen J, Schein EH, Steele F (eds). The Dorsey Press: Homewood Ill.

Van Maanen J. 1979b. The self, the situation, and the rules of interpersonal relations. In Essays in Interpersonal Dynamics, Bennis W, Van Maanen J, Schein EH, Steele F (eds). The Dorsey Press: Homewood Ill.

Willoughby KW. 1990. Technology Choice: A Critique of the Appropriate Technology Movement. Westview Press: Boulder, CO.

Yates J, Orlikowski WJ, Okamura K. 1999. Explicit and implicit structuring of genres in electronic communication: reinforcement and change of social interaction. Organization Science 10: 83-103.

Yoels WC, Clair JM. 1994. Never enough time: how medical residents manage a scarce resource. Journal of Contemporary Ethnography 23: 185-213. 